\section{A computer program for ordered categorical data analysis}

\section{MICHAEL J. GLENCROSS}

Department of Mathematics, University of the Witwatersrand Johannesburg 2001, South Africa

In the behavioral and social sciences, a typical source of ordered categorical data is the response of a group of people to some form of rating scale. Two frequently used rating scales are the Likert-type scale (Edwards, 1957; Likert, 1932) and the semantic differential (Osgood, Suci, \& Tannenbaum, 1957).

In analyzing such scales, the mean and standard deviation of the responses to each item are commonly obtained and an attempt is made to determine whether the sample respondents are or are not generally in agreement. An exact probability test for this purpose has been proposed by Cooper (1976), with important modifications suggested by Whitney (1978).

The program described here calculates the Whitney t statistic for each item, together with an estimate of the probability of its occurrence (Jaspen, 1965), and it provides a nonsubjective estimate of whether or not a particular item "pole" is characteristic of the sample population. It may thus form a useful adjunct to existing programs for the analysis of Likert-type (Antonak, 1980) and semantic differential (Lawson \& Metivier, 1980) rating scales.

Input. The program reads data in the form of responses by item for each respondent. A problem parameter card is used to control for the number of item response alternatives, the number of respondents, and the number of questions.

Output. The printed output provides (1) a respondent by item response matrix, (2) tables showing the number of responses for each item response alternative, together with any invalid responses, for (a) the total number in the sample, as well as for (b) the male and (c) the female subgroups in the sample, (3) the Whitney $t$ statistic for each item, and (4) the associated probability level for each $t$ statistic.

Computer and language. The program is written in standard FORTRAN IV for use on an IBM 370/158 system. Adjustments for use with another computer will depend on the compiler used.

Restrictions. The program has the following restrictions: The maximum number of item response alternatives is seven, and the maximum number of items is 150.

Availability. Copies of this paper and a source listing of the program, with sample data analysis, may be obtained without charge from Michael J. Glencross, Department of Mathematics, University of the Witwatersrand, 1 Jan Smuts Avenue, Johannesburg 2001, South Africa.

\section{RWFERENCES}

Antonak, R. F. A FORTRAN program to analyze summated rating scales. American Statistician, 1980, 34, 59.

Cooper, M. An exact probability test for use with Likert-type scales. Educational and Psychological Measurement, 1976, 36, 647-655.

EDwaRDs, A. L. Techniques of attitude construction. New York: Appleton-Century-Crofts, 1957.

JAsPEN, N. The calculation of probabilities corresponding to values of 2, t, F and chi-square. Educational and Psychological Measurement, 1965, 25, 877-880.

Lawson, E. D., \& Metivier, B. L. Computer programs for the semantic differential: An update and expansion. Behavior Research Methods \& Instrumentation, 1980, 12, 381.

LIKERT, R. A technique for the measurement of attitudes. Archives of Psychology, 1932, 140, 44-53.

Osgoon, C. E., Suci, G. J., \& Tannenbaum, P. The measurement of meaning. Urbana: University of Illinois Press, 1957.

Whitney, D. R. An alternative test for use with Likert-type scales. Educational and Psychological Measurement, 1978, 38, 15-18.

(Accepted for publication August 9, 1981.) 